\title{
Políticas de reparación: Reclamación y reentierro de restos indígenas. El caso de Gregorio Yancamil
}

\section{Rafael Pedro Curtoni and María Gabriela Chaparro}

\section{(2) OpenEdition}

Journals

\section{Electronic version}

URL: http://journals.openedition.org/corpusarchivos/931

DOI: 10.4000/corpusarchivos.931

ISSN: 1853-8037

\section{Publisher}

Diego Escolar

\section{Electronic reference}

Rafael Pedro Curtoni y María Gabriela Chaparro, « Políticas de reparación: Reclamación y reentierro de restos indígenas. El caso de Gregorio Yancamil », Corpus [En línea], Vol 1, No 1 | 2011, Publicado el 30 junio 2011, consultado el 19 abril 2019. URL : http://journals.openedition.org/corpusarchivos/931 ; DOI : 10.4000/corpusarchivos.931

This text was automatically generated on 19 April 2019. 


\title{
Políticas de reparación: Reclamación y reentierro de restos indígenas. El caso de Gregorio Yancamil
}

\author{
Rafael Pedro Curtoni and María Gabriela Chaparro
}

\section{Introducción}

1 En las últimas décadas en la provincia de La Pampa se han desarrollado y mantenido diferentes acciones de homenaje, reconocimiento y restitución vinculadas con la problemática indígena como parte de las políticas estatales de "reparación histórica" con el pueblo rankülche. Desde la década de 1990, diversos monumentos y marcas conmemorativas fueron erigidos en la provincia con la finalidad de identificar y marcar lugares ancestrales y en consideración hacia la cultura rankülche (Curtoni et al. 2003; Curtoni 2004; Lazzari 2007). En la mayor parte de los casos, las autoridades y funcionarios del gobierno provincial han tenido una activa intervención y poder de decisión sobre los contenidos, formas y pertinencias de las políticas de reconocimiento. Ello ha derivado en un manejo hegemónico de los asuntos indígenas y en una participación limitada de las comunidades y representantes involucrados, quedando subsumidos a las acciones e intereses oficiales. En consecuencia, la reparación histórica se demuestra activa con hechos y homenajes que promueven la visibilidad de la cuestión indígena y contribuyen a la construcción de patrimonio, identidad y cultura en sintonía con los ideales de formación y consolidación del Estado-nación. Los productos derivados ofrecen una mirada patrimonialista y estática de lo rankülche que nos dice acerca de sus historias, cosmovisión y reclamos contemporáneos. Entre los hechos de reparación realizados en La Pampa hacia el pueblo rankülche, los más significativos por la trascendencia nacional que adquirieron se encuentran la restitución de los restos del cacique Panguitruz Güor (Mariano Rosas) acaecida en junio del 2001 y el reentierro de Gregorio Yancamil ocurrido en agosto de 2006. En este trabajo discutiremos el último caso mencionado teniendo en cuenta algunas reinterpretaciones de un análisis previo (Curtoni y Chaparro 2007-2008). 


\section{Del cementerio a la plaza central}

2 "Héroes de Cochicó" es el nombre de la plaza principal de la ciudad de Victorica, provincia de La Pampa (Argentina), donde en la actualidad se encuentran enterrados en un monumento restos de soldados del Ejército Nacional y en otro, los restos del capitanejo rankülche José Gregorio Yancamil que se enfrentaron en combate el 19 de agosto de 1882 en el Paraje Cochicó (Hux 2003). Pero esto no siempre fue así.

3 Los restos de los soldados muertos en el denomina-do "Combate de Cochicó" estaban en el cementerio local hasta que autoridades provinciales, habiendo observado con desagrado el estado en que se encontraban, decide trasladarlos y depositarlos en un túmulo construido a tal fin delante de la Iglesia Nuestra Señora de la Merced, frente a la Plaza (Roldán Cesanelli 2010). Luego y en sintonía con el proceso de glorificar e inmortalizar a los patriotas de la narrativa oficial mediante la monumentalización en plazas públicas, casi cuarenta años después de ese combate, en 1923 se construye el monumento "Pirámide de Cochicó" en el centro de la plaza de Victorica y un 19 de agosto son trasladados los restos de los sol-dados y depositados al pie de la misma. A partir de ese momento, autoridades provinciales, del ejército y habitantes de Victorica se congregaron en actos protocolares cada 19 de agosto con el propósito de rendir homenaje a la Batalla de Cochicó y a los soldados muertos que de a poco fueron convirtiéndose en héroes nacionales.

4 Mientras tanto, los restos de Yancamil (1849-1931), jefe rankülche de ese combate, descansaban casi desapercibidos en el cementerio de esa misma localidad hasta el año 2006. En ese año, a través de una decisión política donde participaron los descendientes de Yancamil y representantes del gobierno municipal, sus restos fueron desenterrados del cementerio y reenterrados en la plaza "Héroes de Cochicó" con los honores de un jefe militar. En menos de un siglo, Yancamil pasó de ser el representante de los enemigos de la nación a compartir el lugar central junto a los "Héroes" del ejército que combatió.

5 La ceremonia demandó dos días y empezó el 18 de agosto a la mañana con la exhumación y traslado en procesión de los restos del jefe indígena hasta el salón principal de la Municipalidad, ubicada frente a la plaza central. En la Municipalidad se rindieron honores y homenajes a Yancamil durante todo el día con guardia permanente y visitas de representantes e invitados provinciales, nacionales y público en general. A la mañana siguiente, 19 de agosto, la pequeña urna conteniendo los restos del jefe rankülche fue trasladada hasta la plaza central y depositada en una recámara subterránea del mausoleo construido sobre un lateral de la misma. El monumento/mausoleo donde se encuentran los restos de Yancamil está construido sobre un bloque cuadrangular de mármol crudo proveniente de las sierras de Limay Mahuida (La Pampa). En la parte superior fueron colocadas dos esculturas de zorros para connotar el linaje de pertenencia del cacique, y sobre el lateral que mira hacia la pirámide "Héroes de Cochicó" ubicada en el centro de la plaza fue esculpido un kultrúm, instrumento de percusión considerado sagrado en la cosmovisión indígena. Antes de cerrarse la recámara ubicada debajo del bloque de mármol, se colocó sobre la urna un toki, insignia de mando y símbolo asociado a los jefes indígenas como parte del acompañamiento ritual. Otras actividades fueron realizadas para finalizar con la ceremonia, como danzas nativas, rogativas y discursos pronunciados por descendientes del cacique, el intendente municipal y el gobernador provincial (Mendoza 2007; Curtoni y Chaparro 2007-2008). 
6 Como se desprende de los hechos descriptos, no se trataría de un caso de restitución sino más bien de reclamación. Para los protagonistas se trata de una reparación histórica que incluyó el desentierro, traslado y reentierro, en consonancia con la política de reconocimiento y valorización de la provincia de La Pampa a los poblaciones indígenas y especialmente a los rankülches. Esta política provincial impone a través del discurso de las autoridades oficiales un sentido de reparación e integración, tratando de "borrar" las controversias subyacentes ${ }^{1}$, apelando a la construcción de una nueva identidad "pampeana" basada en la síntesis multicultural. Sin embargo, la decisión de trasladar los restos de Yancamil a la plaza central contó con el expreso acuerdo del pueblo rankülche, según las propias palabras de Luis Dentoni ${ }^{2}$, bisnieto de Yancamil y uno de los principales pro-motores del proyecto: "en el 2005 hicimos una reunión de comunidades para acordar, y si el pueblo ranquel no estaba de acuerdo no se hacía... por suerte estuvieron todos de acuerdo" (Dentoni com. pers. 2006 [entrevista personal]). El pedido de reentierro tuvo el suficiente interés y apoyo político del gobierno municipal y del Estado provincial. Esta sintonía política posibilitó una rápida movilización de la burocracia (contactos, papelería, recursos, intenciones, etc.) en pos de llevar adelante rápidamente la ceremonia (Mendoza 2007). Según el lonko Luis Dentoni, el intendente de la localidad de Victorica y la prensa, el objetivo del traslado era revalorizar "la otra historia" sin haberse manifestado otras intenciones más allá de ese reconocimiento.

7 Al parecer, y como ha ocurrido en otras situaciones, las políticas de reparación histórica impulsadas por el Estado se desarrollan activando simultáneamente procesos de "visibilización genérica" y de "invisibilización específica" (ver Curtoni y Chaparro, 2007-2008:25), resultando por un lado en acciones tangibles de los asuntos indígenas (siendo los monumentos la forma preferida), y por otro en omisión, ocultamiento y/o negación de los reclamos actuales y de las necesidades de las comunidades. Como consecuencia de estos procesos pueden activarse ideas y visiones que tienden a patrimonializar y esencializar sujetos, hechos, luchas y reivindicaciones del mundo indígena.

\section{Discutiendo "restitución" y el después}

8 Las restituciones de restos humanos a las comunidades de pertenencia son acciones políticas cargadas de múltiples y diferentes significaciones y valoraciones para al menos los dos grandes agentes que intervienen en las mismas, los pueblos indígenas y los organismos del Estado. Para estos últimos, en la coyuntura suelen ser funcionales a intereses políticos convencionales consustanciados con los principios de redención del Estado-nación y ejecutados a través de sus representantes. Asimismo, las restituciones sirven al Estado como paliativos temporales para eximirlo de otras acciones de reparación más problemáticas e incómodas a diversos intereses (por ej. multinacionales) como los reclamos de tierras ancestrales. La actual soja-manía en Argentina generó un desmedido avance y corrimiento de la frontera agrícola y una nueva valorización de tierras antes consideradas marginales y/o semidesérticas. Sumado a ello, se encuentran los megaemprendimientos turísticos y mineros en tierras no afectadas por lo agrícola. Todo ello remarca que cada vez más tierras serán necesarias para los proyectos de desarrollo y productivos, con el consecuente impacto y ocupación de los espacios que tradicionalmente ocupan campesinos e indígenas (Curtoni y Chaparro 2008). A partir de esto presuponemos que las restituciones de restos humanos y pertenencias asociados 
conformarán parte de la moneda de cambio resignada por los sectores de poder a favor de la unidad de valor y uso preferida: la tierra.

Por otra parte, para las comunidades originarias parece ser que la reclamación está más allá del objeto/cuerpo demandado y de la acción implicada. Las reclamaciones y a veces restituciones generadas por los actores y/o comunidades indígenas forman parte de estrategias etnopolíticas realizadas en el marco de la cosmovisión y el derecho propio y visualizando las potencialidades y horizontes que pueden promoverse a partir de estos inicios. De esta manera el logro de restituciones señala más bien los comienzos que la finalización de un proceso. Así lo entienden los descendientes rankülche de Yancamil "un símbolo de piedra (el mausoleo/monumento), que como vestigio comenzará a dejar marcas y huellas en toda la comunidad" (discurso del tataranieto de Yanca-mil durante la ceremonia de reentierro). El monumento, como "símbolo" y "vestigio", se constituye en devenir, en activador de otras dimensiones y procesos no siempre previstos ni definitivos. Por lo general, las reclamaciones sustanciadas en restituciones generan actos localizados y acotados en tiempo y espacio, construyen lugares, memorias e identidades. De esa forma, las restituciones devienen en cronotopos etnopolíticos activos, como parte de posicionamientos geopolíticos de las comunidades indígenas, con una serie de alcances potenciales complejos, múltiples y de diferentes escalas temporales.

10 En algunos casos la academia suele entender las reclamaciones bajo la idea de separación entre los vivos y los muertos, amparada en la presunción cartesiana de escisión entre cuerpo y alma. Desde esta visión la reclamación preanuncia la materialidad como condición necesaria de su realización, se demandan cuerpos, restos, objetos, siendo lo tangible de la cosa la representación unívoca del acto performativo. Así lo reclamado y a veces restituido deriva en sujetos/objetos cosificados y patrimonializados. Este entendimiento de la restitución suele también estar acompañado de un sentido práctico y utilitarista de la misma presuponiendo funciones y resultados potenciales más allá de lo pensado y no siempre enunciado por parte de los agentes directamente involucrados. Pareciera ser que desde los ámbitos disciplinares se preestablece la condición de visualizar los efectos y resultados deseados y efectivamente logrados que necesariamente debieran tener las restituciones (ver las discusiones y reflexiones de Jofré 2010; Verdesio 2010, entre otros).

11 Más allá de los beneficios y condiciones de posibilidad que potencialmente detentan y generan los casos de restitución, es claro que los mismos están atravesados por dimensiones políticas y razones que subyacen e impulsan las devoluciones. En ese sentido, las restituciones en sí mismas pueden ser vistas como expresiones de la maquinaria postmoderna y/o como efectos de relaciones de poder/colonialidad más amplias. Entre algunos de los sentidos de colonialidad del poder y del saber, resignificados en estos tiempos, se preestablecen las codificaciones de las diferencias en jerarquías raciales, la negación de la simultaneidad y las "otrizaciones". A la luz de estos procesos planteamos que la restitución de restos indígenas se efectiviza como mecanismo en la medida en que los indígenas son conceptualizados como lo "otro" de la razón occidental. Si no fueran considerados "otros", cosificados y clasificados en esquemas de diferencias, ¿por qué restituirlos? La racionalidad occidental no acostumbra restituir lo propio de su razón.

12 Para finalizar, cuando se consuman los casos de restitución de restos indígenas a las comunidades que los han reclamado, esos hechos suelen considerarse positivos y reparadores de los diferentes procesos de despojo y expoliaciones a los que fueron y aún 
son sometidos los pueblos originarios. En ese contexto, las restituciones son vistas como logros políticos para los grupos indígenas y puntos de inflexión para reafirmar derechos, reclamar territorios, cohesionar y fortalecer al interior de las comunidades, perfilar identidades y pertenencias socia-les y pensar horizontes posibles. En sí mismos los casos de restitución ofrecen diferentes pliegues de un fenómeno complejo, político y creciente. Se podría estimar que en el futuro próximo los casos de restitución de restos indígenas y cultura material se incrementarán atravesados por dos lógicas, porque representan expresiones reparadoras con sentido patrimonialista útiles para redimir algo de la conciencia histórico-política del Estado, y porque constituyen parte del "canje" cedido por los sectores hegemónicos a cambio de la tierra. Más allá de eso los grupos indígenas sostienen luchas y reivindicaciones de largo plazo como parte de estrategias etnopolíticas en las cuales las restituciones son parte de una agenda más amplia y compleja.

Para finalizar nos preguntamos en este escenario acerca de nuestro rol. ¿Estamos en condiciones de exigir participación y/u opinión? ¿Deberíamos permanecer al margen? Consideramos que podemos involucrarnos pero para ello es imprescindible un planteo descolonizador de la disciplina que subvierta la autoridad epistemológica, la neutralidad valorativa y el distanciamiento académico, y promueva el diálogo, la conversación, la discusión, negociación y consenso con las comunidades en cuestión.

\section{BIBLIOGRAPHY}

Curtoni, R. (2004). “La dimensión política de la arqueología: el patrimonio indígena y la construcción del pasado”, en: Martínez, G., Gutiérrez, M., Curtoni, R., Berón, M. y Madrid, P. (Eds.), Aproximaciones contemporáneas a la Arqueología pampeana. Perspectivas teóricas, metodológicas, analíticas y casos de estudio, (pp. 437-449). Olavarría: Facultad de Ciencias Sociales.

Curtoni, R. y Chaparro, M. G. (2007-2008). El re-entierro del cacique José Gregorio Yancamil. Patrimonio, política y memoria de piedra en la pampa argentina. Re-vista Chilena de Antropología, 19, 9-36.

Curtoni, R. y Chaparro, M. G. (2008). El espejo de la naturaleza y la enfermedad histórica en la construcción del conocimiento. Intersecciones en Antropología, 9, 213-227.

Curtoni, R., Lazzari, A. y Lazzari, M. (2003). Middle of nowhere: a place of war memories, commemoration and aboriginal re-emergence (La Pampa, Argentina). World Archaeology, 35 (1), 61-78.

Hux, M. (2003). Caciques Pampa-Ranqueles. Buenos Aires: El Elefante Blanco.

Jofré, I. (2010). “Presentación del regreso de los muertos y las promesas del oro”, en: Jofré, I. (Coord.), El regreso de los muertos y las promesas del oro: patrimonio arqueológico en conflicto (pp. 17-27). Córdoba: Editorial Brujas.

Lazzari, A. (2007). Identidad y fantasma: situando las nuevas prácticas de libertad del movimiento indígena en La Pampa. Quinto Sol Revista de Historia Regional, 11, 91-122. 
Mendoza, M. (2007). Identidad y políticas de reconocimiento: discurso y prácticas en la construcción de la alteridad de los pueblos originarios. Quinto Sol Revista de Historia Regional, 11, 123-142.

Roldán Cesanelli, L. (2010). Sobre Cochicó. http://luis-roldan.blogspot.com/2010/08/sobrecochico.html 2011

Verdesio, G. (2010). “El drama de la restitución de restos humanos y sus actores en Uruguay y Argentina: El Estado, los/las arqueólogos/as y las comunidades de Pueblos Originarias”, en: Jofré, I. C. (Coord.), El regreso de los muer-tos y las promesas del oro: patrimonio arqueológico en conflicto (pp. 123-139). Córdoba: Editorial Brujas.

\section{NOTES}

1. Para interiorizarse de las opiniones de los habitantes de Victorica ver Mendoza (2007).

2. Lonko de la "Comunidad Yancamil" integrada por 80 familias.

\section{AUTHORS}

\section{MARÍA GABRIELA CHAPARRO}

CONICET, INCUAPA, Facultad de Ciencias Sociales, Universidad Nacional del Centro de la Provincia de Buenos Aires.

Correo electrónico: rcurtoni@soc.unicen.edu.ar y chaparro@soc.unicen.edu.ar 